\title{
Aggregation-induced emission behavior of a pincer platinum(II) complex bearing a poly(ethylene oxide) chain in aqueous solution
}

Hiroya Honda, Junpei Kuwabara, Takaki Kanbara*

Tsukuba Research Center for Interdisciplinary Materials Science (TIMS), Graduate School Pure and Applied Sciences, University of Tsukuba, 1-1-1 Tennodai, Tsukuba 305-8573, Japan

* Corresponding author.

Takaki Kanbara

Tsukuba Research Center for Interdisciplinary Materials Science (TIMS), Graduate School Pure and Applied Sciences, University of Tsukuba, 1-1-1 Tennodai, Tsukuba 305-8573, Japan

Tel.: +8129853 5066: fax: +81298534490.

E-mail address: kanbara@ims.tsukuba.ac.jp (T. Kanbara). 


\begin{abstract}
An amphiphilic pincer platinum(II) complex with a poly(ethylene oxide) (PEO) chain exhibited aggregation-induced emission (AIE) because of micelle formation in water. The AIE activity was enhanced by the addition of 1,3,5-benzenetricarboxylic acid, which induced micelle formation through hydrogen-bonding interactions with the PEO chain.
\end{abstract}

Keywords: Aggregation-induced emission, Pincer platinum complex, Poly(ethylene oxide), Micelle formation 


\section{Introduction}

Amphiphilic molecules bearing both hydrophobic and hydrophilic moieties tend to form micelles via self-assembly in water [1]. The aggregation state of micelles can be controlled by external stimuli such as temperature, $\mathrm{pH}$, and metal ions [2]. In addition, micelles can incorporate additives such as emissive hydrophobic dyes [3]. The response of emissive micelles to external stimuli makes the micelles promising for potential applications in emission sensors [3,4]. However, the luminescent efficiency of conventional luminophores is often weak in aggregates such as micelles (aggregation-caused quenching, ACQ) [5]. In contrast to the ACQ phenomenon, Tang's group in 2001 reported a luminophore that exhibited efficient emission when aggregated, even though it was nonemissive in the dilute solution [6]. This luminescent phenomenon is termed as aggregation-induced emission (AIE). The main factor for the observation of AIE is the restriction of molecular motion in the aggregate state [6,7]. In general, AIE is observed when the AIE-active molecules form aggregates in a mixed solvent containing an organic solvent (good solvent) and water (poor solvent) [8]. However, amphiphilic compounds with an AIE-active segment can show AIE activity in aqueous solutions because these compounds can self-assemble to form micelles through hydrophobic interactions [4].

Recently, we reported the AIE properties of secondary thioamide-based platinum complex $\mathbf{1}$, $\left[\mathrm{Pt}\left({ }^{\mathrm{Bn}} \mathrm{S}^{\wedge} \mathrm{C}^{\wedge} \mathrm{S}\right)\left(\mathrm{PPh}_{3}\right)\right] \mathrm{Cl} \quad\left({ }^{\mathrm{Bn}} \mathrm{S}^{\wedge} \mathrm{C}^{\wedge} \mathrm{S}=N, N^{\prime}\right.$-dibenzyl-1,3-benzenedicarbothioamide, $\mathrm{PPh}_{3}=$ triphenylphosphine) [9]. The AIE activity of 1 was caused by the suppression of molecular motion resulting from aggregate formation upon addition of the poor solvent to the solution. This result prompted us to explore the idea that an amphiphilic complex with the AIE-active $\left[\mathrm{Pt}\left({ }^{\mathrm{Bn}} \mathrm{S}^{\wedge} \mathrm{C}^{\wedge} \mathrm{S}\right)\left(\mathrm{PPh}_{3}\right)\right]^{+}$segment could exhibit AIE activity in water owing to micelle formation. Poly(ethylene oxide) (PEO) is often used as a hydrophilic moiety in amphiphilic molecules that form micelles [10]. For example, the amphiphilic compound bearing a PEO chain $\left(M_{\mathrm{n}}=2000\right)$ was reported to form micelles [10b]. Hence, to achieve the AIE activity through micelle formation with an amphiphilic metal complex, we introduced a PEO chain $\left(M_{\mathrm{n}}=2000\right)$ into $\left.\left[\mathrm{Pt}^{\mathrm{Bn}} \mathrm{S}^{\wedge} \mathrm{C}^{\wedge} \mathrm{S}\right)\left(\mathrm{PPh}_{3}\right)\right]^{+}$ 
and prepared an amphiphilic complex 2 (Fig. 1). The addition of some hydrophobic compounds is known to enhance micelle formation via desolvation caused by a hydrogen-bonding interaction between the additives and the PEO chains, which serve as a guest recognition site [11]. The enhancement of micelle formation for the AIE-active amphiphilic compound is expected to increase the AIE activity $[4 \mathrm{a}, 8,12]$. Indeed, the AIE activity of the poly( $N$-isopropylacylamide)-based micelle increased with the enhancement of micelle formation via desolvation induced by heating [4a]. In this study, the PEO chain is also used as a recognition site for hydrogen-bonding guest molecules that induce micelle formation. Herein, we report AIE activity of $\mathbf{2}$ resulting from the restriction of molecular motion caused by micelle formation and the enhanced AIE activity as a result of hydrogen-bonding interactions between the additive and the PEO chain (Fig. 1).

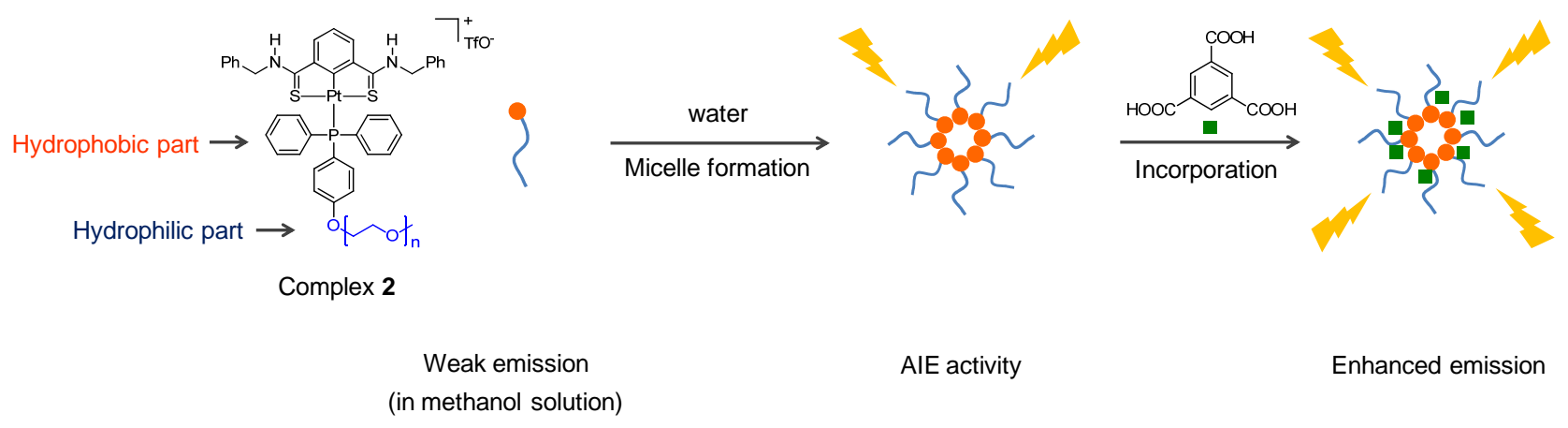

Fig. 1. Schematic representation of self-assembled micelle of complex $\mathbf{2}$ in water.

\section{Results and discussion}

Amphiphilic complex 2 was prepared by reacting $\left[\mathrm{Pt}^{\mathrm{Bn}} \mathrm{S}^{\wedge} \mathrm{C}^{\wedge} \mathrm{S}\right) \mathrm{Cl}$ ] [13] with the hydrophilic phosphine ligand [14] followed by treatment with AgOTf (Scheme S1). As expected, complex 2 was soluble both in organic solvents and in water. Complex 2 was characterized by ${ }^{1} \mathrm{H}$ NMR in methanol- $d_{4}$, THF- $d_{8}$, and acetone- $d_{6}$ (Figs. 2a, 2b, and Fig.S1). To examine the self-assembly of 2 , the ${ }^{1} \mathrm{H}$ NMR spectrum of $\mathbf{2}$ in $\mathrm{D}_{2} \mathrm{O}$ was measured. The proton signals of $\mathbf{2}$ in $\mathrm{D}_{2} \mathrm{O}$ were broad and 
weak (Fig. 2c), whereas those in the organic solvents were sharp (Figs. 2a and 2b). These results suggest that $\mathbf{2}$ forms micelles by self-assembly in water.

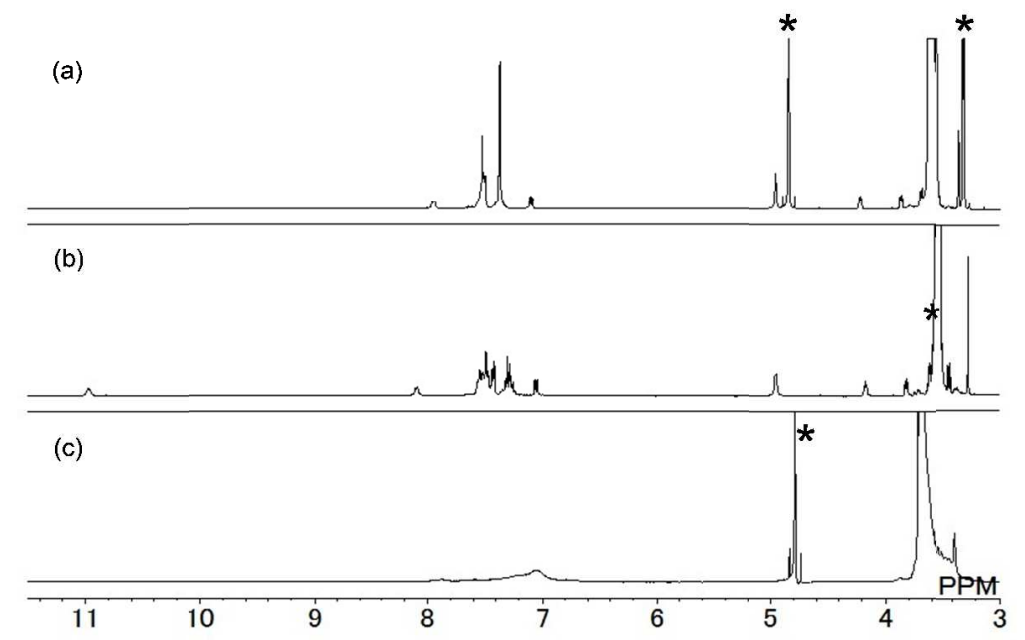

Fig. 2. ${ }^{1} \mathrm{H}$ NMR spectra of $2(3 \mathrm{mM})$ in methanol- $d_{4}(\mathrm{a}), \mathrm{THF}-d_{8}(\mathrm{~b})$, and $\mathrm{D}_{2} \mathrm{O}$ (c) (* indicates signals from the solvent).

For further confirmation of micelle formation by $\mathbf{2}$ in water, absorption spectra of $\mathbf{2}$ were obtained in the presence of the hydrophobic dye Nile Red (NR), which served as a probe for micelle formation [1b]. The absorption peak of NR could not be detected in water because of its poor solubility $[1 \mathrm{~b}, 15]$. The absorbance of NR was constant and low at low concentrations of $\mathbf{2}$, but was significantly increased once a certain concentration of $\mathbf{2}$ was reached (Fig. S2). This result indicated that NR was incorporated into a hydrophobic environment that was only present above a specific concentration of $\mathbf{2}$. This is consistent with micelle formation by $\mathbf{2}$ in water [1 b]. The critical micelle concentration (CMC) of 2 in the presence of NR was $2.6 \times 10^{-5} \mathrm{M}$ (Fig. S2). In addition, micelles of 2 in water were also confirmed by dynamic light scattering (DLS) experiments and atomic force microscopy (AFM) images (Figs. S3a and S4). 
The absorption and emission spectra of $\mathbf{2}$ in methanol were almost the same as those of $\mathbf{1}$ (Fig. S5), which exhibits emission through metal-to-ligand charge transfer (MLCT) excited states [9]. These results suggested that MLCT excited states were also involved in the emission of 2 . The quantum yield of $\mathbf{2}$ in methanol was 0.016. As shown in the NMR experiments above, complex $\mathbf{2}$ is not aggregated in methanol whereas micelles are formed in water. To examine the effects of micelle formation on the AIE activity, the emission spectra of $\mathbf{2}$ in methanol/water mixtures were measured (Fig. 3). The emission spectrum of $\mathbf{2}$ exhibited an increase in the emission intensity upon increasing the proportion of water in the methanol/water mixtures. The emission intensity in water was 4.4 times higher than that in the methanol solution. This result indicates that $\mathbf{2}$ is AIE-active in water. The emission wavelength of 2 in water $\left(\lambda_{\mathrm{em}}=622 \mathrm{~nm}\right)$ shifted to lower energy compared to that in the methanol solution $\left(\lambda_{\mathrm{em}}=601 \mathrm{~nm}\right)$. The wavelength of emission through MLCT excited states often depends on solvent polarity [16]. Therefore, the red shift observed in water was attributed to the increased solvent polarity around the chromophore [9].

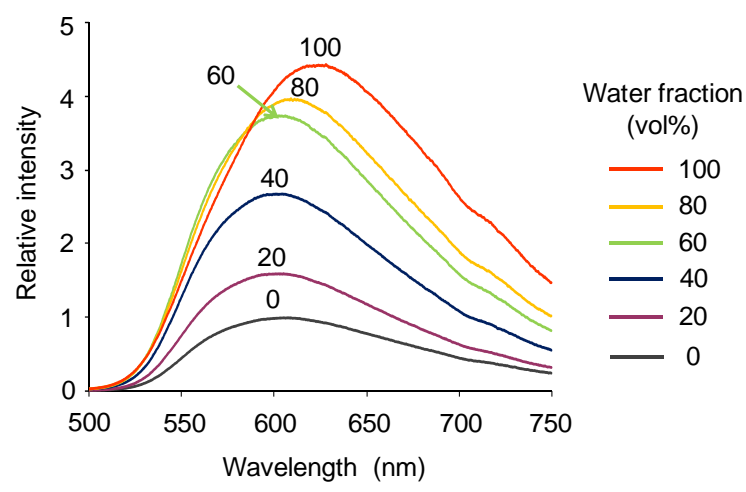

Fig. 3. Emission spectra of 2 in methanol/water mixtures $\left(5 \times 10^{-5} \mathrm{M}, \lambda_{\mathrm{ex}}=385 \mathrm{~nm}\right)$.

In terms of micelle formation, hydrophobic benzoic acid derivatives are known to be incorporated into PEO moiety by hydrogen-bonding interactions [17], therefore, the effects of adding 
1,3,5-benzenetricarboxylic acid (trimesic acid) to $\mathbf{2}$ on the AIE activity were investigated. A significant enhancement of the emission intensity of $\mathbf{2}$ was observed by increasing the amount of trimesic acid in the aqueous solution (Fig. 4). When 75 equivalents (eq.) of trimesic acid were added, the emission intensity of $\mathbf{2}$ was 4.2 times higher than that for $\mathbf{2}$ without trimesic acid in aqueous solution. In addition, a blue shift in the emission wavelength of 2 (from 620 to $597 \mathrm{~nm}$ ) was observed upon adding trimesic acid. Hydrogen-bonding interactions between the PEO chain and the additive are known to cause desolvation of the PEO chain [11]. Thus, the blue shift could arise from the decrease in polarity near the chromophore of $\mathbf{2}$ by desolvation of the PEO chains through hydrogen-bonding interactions with trimesic acid [9]. As a control experiment, the emission spectra of $\mathbf{2}$ in THF upon addition of trimesic acid were measured (Fig. S6), the addition of trimesic acid did not significantly change the emission intensity of $\mathbf{2}$ in THF. This result indicated that interaction between trimesic acid and micelles of $\mathbf{2}$ contributed to the enhanced AIE activity in water. Next, hydrophilic mellitic acid was added to the aqueous solution of 2 instead of trimesic acid (Fig. S7). The enhancement in the emission intensity of 2 with mellitic acid was less than that of 2 with trimesic acid, presumably owing to the hydrophilic nature of mellitic acid.

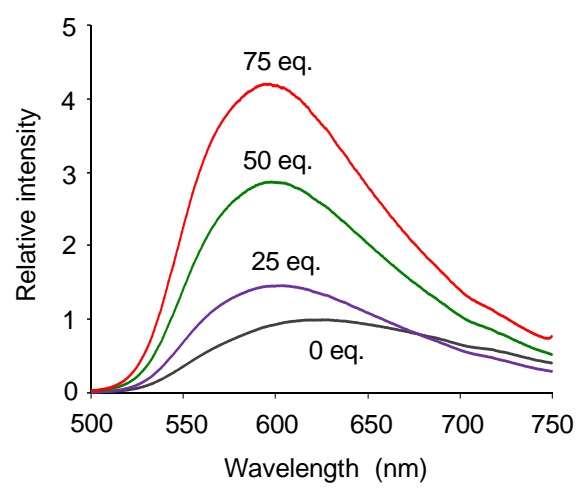

Fig. 4. Changes in emission spectra of 2 (in water, $5 \times 10^{-5} \mathrm{M}, \lambda_{\mathrm{ex}}=385 \mathrm{~nm}$ ) upon the addition of trimesic acid. 
The NR incorporation experiment was also conducted in the micelles of $\mathbf{2}$ with and without trimesic acid. The absorption of NR $(590 \mathrm{~nm})$ increased as the amount of trimesic acid in the aqueous solution of $\mathbf{2}$ was increased (Fig. S8), indicating that the micelle formation of $\mathbf{2}$ was induced by the incorporation of trimesic acid.

The micelle formation of $\mathbf{2}$ with trimesic acid was also confirmed by DLS experiments (Fig. S3). The particle size of $\mathbf{2}$ with 75 eq. trimesic acid was significantly larger $(\sim 1233 \mathrm{~nm})$ than that of $\mathbf{2}$ without trimesic acid ( $\sim 59$ and $\sim 497 \mathrm{~nm})$. A precipitate was formed in the aqueous solution of 2 with 75 eq. trimesic acid after the solution was left to stand for 20 hours. After filtration to remove the precipitate, the absorption and emission intensities of $\mathbf{2}$ in solution were significantly decreased (Fig. S9). This result indicated that the micelles of $\mathbf{2}$ aggregated because of the desolvation of the PEO chain. Therefore, the enhanced AIE activity of $\mathbf{2}$ in aqueous solution is caused by the effective suppression of molecular motion of the chromophore of $\mathbf{2}$ owing to micelle formation induced by desolvation through the formation of hydrogen bonds between the PEO chain and trimesic acid.

\section{Conclusions}

The introduction of the PEO chain to the emissive platinum(II) complex enabled the metal complex to form micelles in aqueous solution. This micelle formation by self-assembly results in AIE activity in water. The PEO chain also serves as a recognition site for trimesic acid, this interaction contributes to the enhancement of AIE activity. The enhanced AIE activity is caused by the hydrogen-bonding interactions between the PEO chain and trimesic acid, which provides a new avenue for AIE activity in micelles. These results provide valuable information for the design of AIE-active emission sensors in water. 


\section{Experimental section}

\subsection{General Procedures}

$\mathrm{CH}_{3}\left(\mathrm{OCH}_{2} \mathrm{CH}_{2}\right)_{\mathrm{n}} \mathrm{OH}\left(M_{\mathrm{n}}=2000\right)$ was purchased from Aldrich. The hydrophilic phosphine ligand was prepared according to the method reported in the literature [14]. All NMR spectra were obtained with a BRUKER AVANCE-400S. Average particle sizes of aggregates were measured by dynamic light scattering (FDLS3000, Otsuka Electronics). Atomic force microscopy (AFM) image was obtained with a Hitachi High-Tech Science E-sweep. The absorption spectra were recorded on a JASCO V-630 spectrometer. The emission spectra were recorded on a Hitachi F-2700 spectrophotometer. Luminescent quantum yield was obtained by a Hamatsu photonics C9920-02.

\subsection{Synthesis of complex 2}

A mixture of $\left.\left[\mathrm{Pt}^{\mathrm{Bn}} \mathrm{S}^{\wedge} \mathrm{C}^{\wedge} \mathrm{S}\right) \mathrm{Cl}\right][13](13.3 \mathrm{mg}, 0.022 \mathrm{mmol})$ and the hydrophilic phosphine ligand [14] (55.2 $\mathrm{mg}, 0.02 \mathrm{mmol})$ was stirred in anhydrous dichloromethane $(1.5 \mathrm{~mL})$ for $30 \mathrm{~min}$ at room temperature under nitrogen atmosphere. The mixture was filtered through Celite and the resulting solution evaporated in vacuo. AgOTf $(5.6 \mathrm{mg}, 0.022 \mathrm{mmol})$ and anhydrous dichloromethane (1.5 $\mathrm{mL}$ ) were added to the residue. After $30 \mathrm{~min}$ of stirring at room temperature under nitrogen atmosphere, the mixture was filtered through Celite and the resulting solution evaporated in vacuo to give $2(68.2 \mathrm{mg}, 98 \%) .{ }^{1} \mathrm{H}$ NMR $\left(400 \mathrm{MHz}\right.$, aceotne- $\left.\mathrm{d}_{6}\right): \delta=10.67(\mathrm{~s}, 2 \mathrm{H}), 8.09(\mathrm{~d}, J=7.4 \mathrm{~Hz}$, 2H), 7.60-7.58 (m, 12H), 7.48-7.37 (m, 11H), $7.17(\mathrm{~d}, J=7.4 \mathrm{~Hz}, 2 \mathrm{H}), 5.06(\mathrm{~s}, 4 \mathrm{H}), 4.26(\mathrm{t}, J=4.4$ $\mathrm{Hz}, 2 \mathrm{H}), 3.87$ (t, $J=4.4 \mathrm{~Hz}, 2 \mathrm{H}), 3.74-3.40$ (br, PEO backbone), 3.29 (s, 3H) ppm. ${ }^{19} \mathrm{~F}\left\{{ }^{1} \mathrm{H}\right\} \mathrm{NMR}$ $\left(376 \mathrm{MHz}\right.$, aceotne-d $\left.\mathrm{d}_{6}\right): \delta=-78.96 \mathrm{ppm} .{ }^{31} \mathrm{P}\left\{{ }^{1} \mathrm{H}\right\}$ NMR $\left(162 \mathrm{MHz}\right.$, aceotne-d $\left.\mathrm{d}_{6}\right): \delta=17.26[J(\mathrm{Pt}, \mathrm{P})$ $=1114.2 \mathrm{~Hz}] \mathrm{ppm}$.

\subsection{Critical micelle concentration of $\mathbf{2}$ by dye incorporation}

Critical micelle concentration of $\mathbf{2}$ was determined according to the method reported in the literature [18]. A $20 \mu \mathrm{L}$ aliquot of a $2.0 \times 10^{-3} \mathrm{M}$ solution of Nile Red (NR) in methanol was 
transferred to $2 \mathrm{~mL}$ of an aqueous solution $2\left(7.6 \times 10^{-6}\right.$ to $\left.5.8 \times 10^{-5} \mathrm{M}\right)$. The solutions were kept in the dark for 20 hours. The absorbance at $585 \mathrm{~nm}$ was recorded at an ambient temperature.

\subsection{Incorporation of trimesic acid by 2}

Incorporation was conducted by reference to the literature [3]. A certain amount of trimesic acid (0-75 equivalent for 2$)$ were added to the aqueous solution of $2\left(5 \times 10^{-5} \mathrm{M}\right)$. The suspended mixture were irradiated by ultrasound for $5 \mathrm{~min}$ and vigorously stirred for $15 \mathrm{~min}$ at room temperature. The mixture were kept in the dark for 60 min. After removal of undissolved trimesic acid through kiriyama filter paper (pore size: $1 \mu \mathrm{m}$ ), the absorption andspectra, emission spectra, and average particle sizes of the resulting solution were measured within $15 \mathrm{~min}$ after the preparation of solution.

\subsection{Incorporation of trimesic acid and Nile Red by 2}

Incorporation was conducted by reference to the literature [3,18]. Trimesic acid (25 or 50 equivalent for 2) were incorporated into $2\left(5 \times 10^{-5} \mathrm{M}\right)$ according to the incorporation method of trimesic acid by $\mathbf{2}$. The incorporation of Nile Red into $\mathbf{2}$ containing trimesic acid was in the same manner as critical micelle concentration of $\mathbf{2}$ by dye incorporation.

\section{Acknowledgements}

The authors thank to the Chemical Analysis Center of University of Tsukuba for the measurements of AFM and DLS experiments. Prof. T. Nabeshima and Dr. M. Yamamura are grateful for the support of quantum yield measurements. This work was supported by the Japan Science Society (Sasakawa Scientific Research Grant).

\section{Appendix A. Supporting information}

Supplementary data related to this article can be found at http:// 


\section{References}

[1] (a) A. G.-Martínez, Y. Vida, D. D.-Gutiérrez, R. Q. Albuquerque, L. D. Cola, Inorg. Chem. 47 (2008) 9131-9133;

(b) T. Taira, Y. Suzaki, K. Osakada, Chem. Asian J. 3 (2008) 895-902;

(c) E. Valls, A. Solsona, J. Suades, Organometallics 21 (2002) 2473-2480.

[2] (a) V. W.-W. Yam, Y. Hu, K. H.-Y. Chan, C. Y.-S. Chung, Chem. Commun. (2009) 6216-6218;

(b) J. Bigot, B. Charleux, G. Cooke, F. Delattre, D. Fournier, J. Lyskawa, L. Sambe, F. Stoffelbach, P. Woisel, J. Am. Chem. Soc. 132 (2010) 10796-10801;

(c) X.-J. Wang, L.-B. Xing, F. Wang, G.-X. Wang, B. Chen, C.-H. Tung, L.-Z. Wu, Langmuir 27 (2011) 8665-8671.

[3] K. Kondo, A. Suzuki, M. Akita, M. Yoshizawa, Angew. Chem. Int. Ed. 52 (2013) 2308-2312.

[4] (a) C.-M. Yang, Y.-W. Lai, S.-W. Kuo, J.-L. Hong, Langmuir 28 (2012) 15725-15735;

(b) Y.-W. Lai, S.-W. Kuo, J.-L. Hong, RSC Adv. 2 (2012) 8194-8200;

(c) B. Han, N. Zhou, W. Zhang, Z. Cheng, J. Zhu, X. Zhu, J. Polym. Sci. Part A: Polym. Chem. $51(2013)$ 4459-4466;

(d) C. Y-S. Chung, V. W.-W. Yam, Chem. Eur. J. 19 (2013) 13182-13192.

[5] M. D. Watson, A. Fechtenkötter, K. Müllen, Chem. Rev. 101 (2001) 1267-1300.

[6] J. Luo, Z. Xie, J. W. Y. Lam, L. Cheng, H. Chen, C. Qiu, H. S. Kwok, X. Zhan, Y. Liu, D. Zhu, B. Z. Tang, Chem. Commun. (2001) 1740-1741.

[7] J. Shi, N. Chang, C. Li, J. Mei, C. Deng, X. Luo, Z. Liu, Z. Bo, Y. Q. Dong, B. Z. Tang, Chem. Commun. 48 (2012) 10675-10677.

[8] (a) Y. Hong, J. W. Y. Lam, B. Z. Tang, Chem. Commun. (2009) 4332-4353;

(b) Y. Hong, J. W. Y. Lam, B. Z. Tang, Chem. Soc. Rev. 40 (2011) 5361-5388.

[9] H. Honda, Y. Ogawa, J. Kuwabara, T. Kanbara, Eur. J. Inorg. Chem. (2014) 1865-1869.

[10] (a) K. Kataoka, G. S. Kwon, M. Yokoyama, T. Okano, Y. Sakurai, J. Control Release 24 (1993) 119-132; 
(b) C. M. Remsberg, Y. Zhao, J. K. Takemoto, R. M. Bertram, N. M. Davies, M. L. Forrest, Pharmaceutics 5 (2013) 81-93.

[11] Y. Tokuoka, H. Uchiyama, M. Abe, K. Ogino, J. Colloid Interface Sci. 152 (1992) 402-409.

[12] J. Kuwabara, Y. Ogawa, A. Taketoshi, T. Kanbara, J. Organomet. Chem. 696 (2011) 1289-1293.

[13] K. Okamoto, T. Yamamoto, M. Akita, A. Wada, T. Kanbara, Organometallics 28 (2009) 3307-3310.

[14] A. Köllhofer, H. Plenio, Chem. Eur. J. 9 (2003) 1416-1425.

[15] L.-B. Xing, S. Yu, X.-J. Wang, G.-X. Wang, B. Chen, L.-P. Zhang, C.-H. Tung, L.-Z. Wu, Chem. Commun. 48 (2012) 10886-10888.

[16] C.-C. Ko, J. W.-K. Siu, A. W.-Y. Cheung, S.-M. Yiu, Organometallics 30 (2011) 2701-2711.

[17] (a) M. Donbrow, C. T. Rhodes, J. Pharm. Pharmacol. 18 (1966) 424-428;

(b) P. Mukerjee, J. Pharm. Sci. 60 (1971) 1528-1531.

[18] D. Takeuchi, A. Inoue, F. Ishimaru, K. Osakada, J. Polym. Sci. Part A: Polym. Chem. 47 (2009) 959-972. 